\title{
"A Smart Vehicle with Battery Charging Using Solar Energy Having Accident Detection and Theft Control System with GSM and GPS"
}

\author{
Komal D. Borkar ${ }^{1}$, Rupali Dasarwar ${ }^{2}$ \\ ${ }^{I}$ M.Tech Student. ${ }^{2}$ Assitant Professor. \\ Electronics Engineering, Wainganga College of Engineering and Management, Dongargaon, Nagpur, India
}

DOI: 10.46335/IJIES.2020.5.10.10

\begin{abstract}
The vast increase in fuel demand for vehicle and vast decrease in the level of fuel day by day is the serious problem. And the fuel engine vehicles release harmful gasses causing air pollution and thereby increasing the diseases related to lungs. The global warming is also the most serious problem the world facing. The solution to these problems is the efficient use of nonrenewable energy source such as solar energy for charging the vehicle battery using solar panel.The rise in technology has increased the rate of road accidents which causes huge loss of life. The poor emergency facilities available in our country just add to this problem. Our project is going to provide a solution to this problem. According to our project when a vehicle meets with an accident, the sensors situated on the vehicle will detect it immediately and send a message to the microcontroller. The microcontroller then sends the alert message and location with the help of GSM and GPS modem to the relatives, a police control room or rescue team in actual case which will include the location with the help of GPS. In case there is no casualty the driver can terminate the alert message by a switch provided in the vehicle. This will save the valuable time of rescue team. The system can also be used for theft detection. Fomite trailing and locking the organization of rules installing in vehicle, to track the place and locking engine motor. The exact location of vehicle identified using GPS and GSM systems. This will continuously track location of theft vehicle and report the status to users. GSM send SMS to controller, respected person need to send password to controller to restart the vehicle and outdoors the door.
\end{abstract}

Keywords-A solar panel,voltage booster, microcontroller, GPS and GSM modules for alert messages. MPLAB IDE.

\section{I- INTRODUCTION}

$\mathbf{N}$ ow-a-day the world facing the most serious problem is the energy demand. Our main demand is the fuels used in automobiles and it causes the major impact to our environment. And also Global warming becomes a most dangerous problem in now a day. This increases the heat in the earth surface and makes the ice peaks to melt down this increases the sea level will be dangerous to the entire world mainly because of the pollution. The main polluting factor is the automobiles which emit the carbon monoxide had a very harmful impact to the environment. So we step into the use of Non-renewable energywhich will be eco-friendly to our environment and also protects the people from inhaling of hazardous carbon monoxide and leads a people to live in a healthy environment. So we had introduced a system for the vehicles which will efficiently use solar energy as a non-renewable energy source for charging vehicle battery by using solar panel.

The advent of technology has also increased the traffic hazards and the road accidents.Due to the lack of best emergency facilities available in our country the lives of the people are under high risk. An automatic alarm device for vehicles is introduced in this paper which can detect accidents with the use of a vibration sensor and sends an alert messageby using GPS -GSM modem to rescue team (may involve police control room, medical team, or relatives of victim) in significantly less time which will help in saving the lives of the people. The alert message contains the geographical location and time in which the accident has occurred. In case there is no casualty, the message can be terminatedwith the help of a switch in order to avoid wasting the valuable time of the rescue team. When an accident occurs it is detected with help of a sensor which activates the device, the sensor gives its output to the microcontroller. A microcontroller is used to communicate sensor output to GSM-GPS module and also displays location on LCD. This system also detects the overheating of vehicle engine which may cause severe problem to 
vehicle and may be to driver.The temperature sensor used in this system gives its output to microcontroller and then microcontroller stops the engine automatically.

Various technologies have been introduced in recent years to detect car theft. In this project we are also going to track the vehicle by using GPS -GSM modem. LCD display used for display values of latitude and longitude of vehicle location. Buzzer is used to detect the vehicle by using sound of buzzer.

\section{METHODOLOGY}

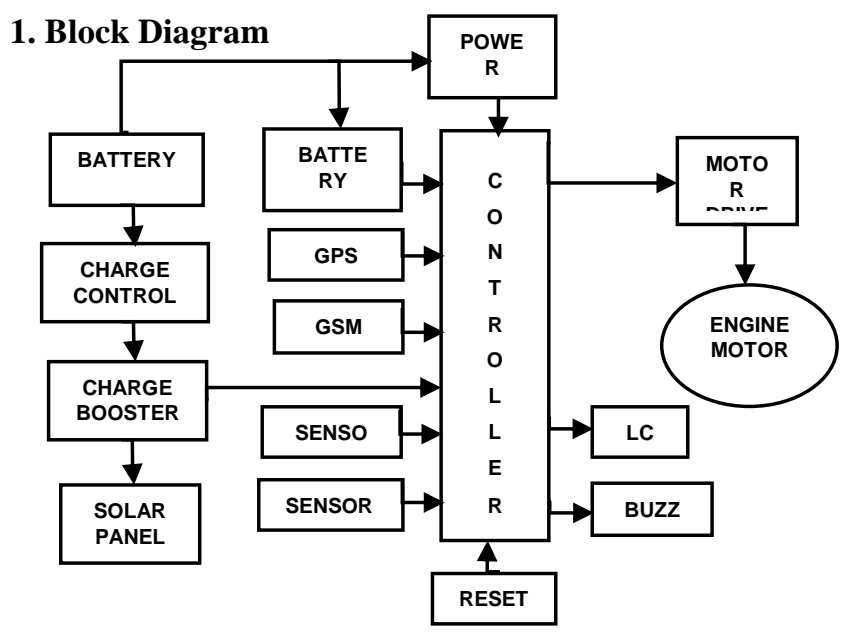

Fig.-1: Block diagram of a smart vehicle system

\section{Hardware Description}

Solar Panel:A solar panel is also called as PV panel, used to convert light energy of the sun into electric energy that can be used to power electrical loads. It can be used in several applications, but in this project we had used it to charge battery of vehicle, so we used $12 \mathrm{~V}, 20 \mathrm{~W}$ solar panel.

Solar panels are comprised of several individual solar cells which are themselves composed of layers of silicon, phosphorous (provides negative charge), and boron (provides positive charge).

Battery:As our vehicle needs battery of $12 \mathrm{~V}$ to drive engine, hence we had used $12 \mathrm{~V}$ battery.

Voltage Booster:In case there is low sunlight as in rainy season, so we need to boost up the solar panel output to drive engine continuously and efficiently, we used voltage booster circuit which is the combination of an inductor, MOSFET, diode and capacitor. The output of booster also depends on duty cycle of wave of driving switch.

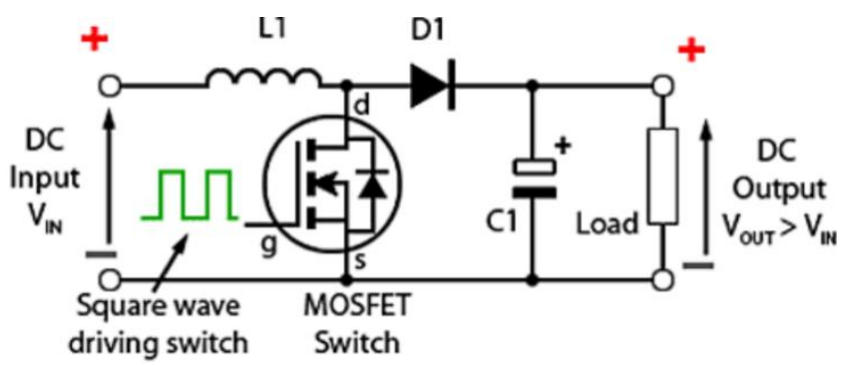

Fig.-2: Basic circuit diagram of voltage Booster

Charge Converter/ Charge controller:A charge converter is basically a voltage and/or current regulator to keep batteries from overcharging. It regulates the voltage coming from voltage booster(boosted voltage of solar panel) prior to vehicle battery, so that battery will prevent to get damage from overcharging.

GPS Module:Each GPS satellite transmits radio signals that enable the GPS receivers in your vehicle to estimate the satellite's location, as well as the distance between it and your vehicles. The receivers then use these measurements to calculate where your vehicles are located on earth and convert the calculations into geodetic latitude and longitude. A receiver needs signals from three GPS satellites to pinpoint position of your vehicle.

\section{GSM (Global System for Mobile Communication)} Module:A GSM module is a wireless modem that works with a GSM wireless network. A wireless modem behaves like a dial-up modem. The main difference between them is that a dial-up modem sends and receives data through a fixed telephone line while a wireless modem sends and receives data through radio waves. Like a GSM mobile phone, a GSM modem requires a SIM card from a wireless carrier in order to operate.The GSM sends the message with the location to the pre saved numbers. It is also used to control and monitor the load from anywhere by sending a message.

In this system GSM Module is used to send alert messages with the time and location to the pre saved numbers, when engine overheated, when accident detected and when vehicle has been stolen within a few seconds.

Sensors:This model also present temperature(LM35) to monitor engine temperature and vibration sensor (ADXL335) to monitor tilting of vehicle when vehicle meets with accident.

Microcontroller:A microcontroller is a compact integrated circuit sometimes referred to as an embedded controller or microcontroller unit (MCU) designed to govern a specific 


\section{International Journal of Innovations in Engineering and Science, Vol 5, No.10, 2020}

$w w w . i j i e s . n e t$

operation in an embedded system. It is embedded inside of a system to control a singular function in a device. It does this by interpreting data it receives from its I/O peripherals using its central processor. The temporary information that microcontroller receives is stored in its data memory, where the processor accesses it and uses instructions stored in its program memory to decipher and apply the incoming data. It then uses its I/O peripherals to communicate and enact the appropriate action.

Microcontrollers are found in various applications such as in vehicles, robots, office machines, medical devices, mobile radio transceivers, vending machines, home appliances, and many other devices. In this system PIC18F2522 microcontroller series is used which has following specific features:

- Package of 28-pin DIP, 28-pin SOIC

- Program memory of 32 Kbytes

- Data memory of 1536 bytes

- EEPROM of 256bytes

- Three I/O ports A, B, C

- 4 Timers

- 17 Interrupt sources

- Detects Low-voltage

LCD:AnLCD is an electronic display module that uses liquid crystal to produce a visible image and commonly used in various devices and circuits. A $2 \times 16$ LCD displayis used in this system to display battery voltage, panel voltage, boosted voltage, location of vehicle, engine temperature, degree of tilting in all 3 axes.A $2 \times 16$ LCD display which has 2 lines and 16 characters per lineand each character is displayed in a $5 \times 7$ pixel matrix. It has 14 pin configuration described as follows.

- Pin1-Vss: ground pin connected to system ground

- Pin2-Vdd $(+5 \mathrm{~V})$ : powers the LCD with $+5 \mathrm{~V}$

- Pin3-V $\square \mathrm{E}$ : decides the contrast level of display, grounded to get maximum contrast

- Pin4-RS (register select): connected to microcontroller to shift between command/data register

- Pin5-RW(read/write): used to read or write data.

- Pin6-Enable: connected to microcontroller pin and toggled between land 0 for data acknowledgement

- Pin(7to14)-data pins: this LCD operates on 4-bit mode hence pin7 to pin10 are free and pin11 to pin14 are connected to pin25 to pin28 of microcontroller
BUZZER: Buzzer is used to alert the driver in case of overheating of engine, also in case when panel voltage is very low and engine should drive on fuel automatically.

RESET: The reset button is used to reset the microcontroller at any stage of work. It can be used to terminate the sending of the message. If the reset switch is pressed, the microcontroller restarts and the function will start from the beginning.

\section{Circuit Diagram}

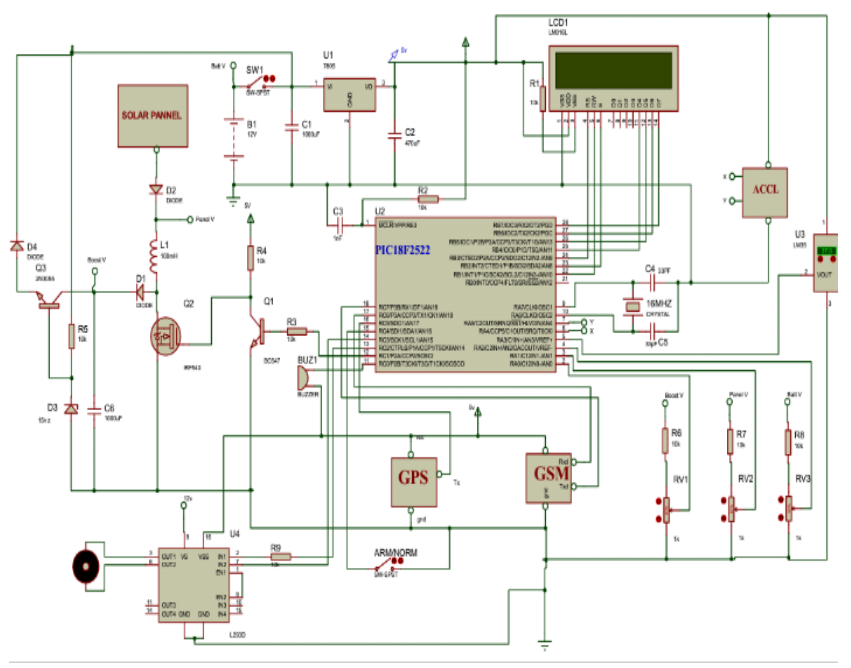

Fig.-3: Circuit diagram of a system(made in PROTEUS)

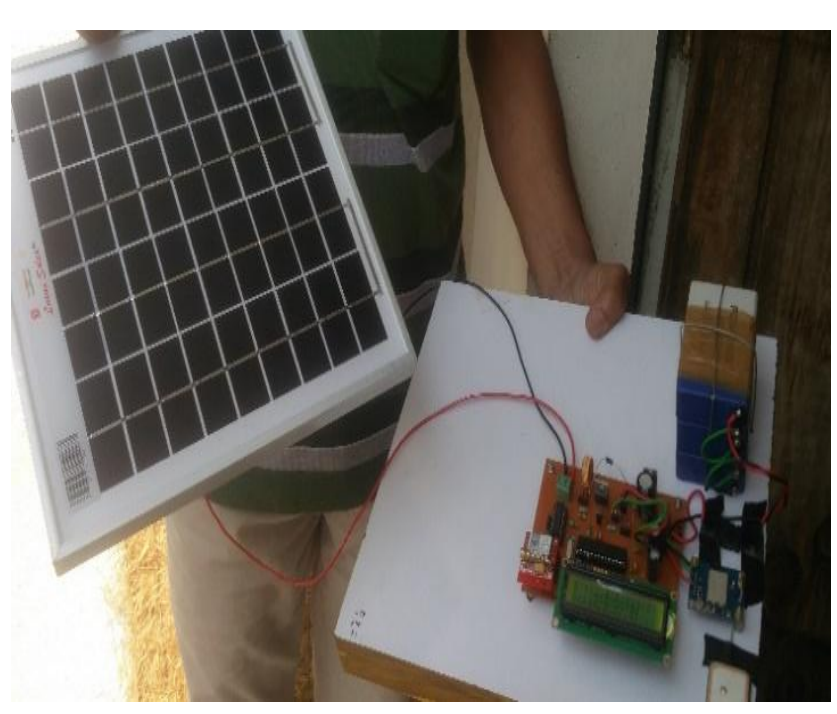

Fig.-4: Hardware of a system 


\section{International Journal of Innovations in Engineering and Science, Vol 5, No.10, 2020}

$w w w . i j i e s . n e t$

\section{Working}

In our project the main component used is solar panel of $12 \mathrm{~V}, 20 \mathrm{~W}$ which will charge efficiently by solar radiation. This panel can give the output of $16 \mathrm{~V}$ to $20 \mathrm{~V}$. The panel is connected to the charge booster (voltage amplifier) and then to charge controller. The charge booster can amplify the voltage equals to three timesthe panel voltage according to duty cycle of PWM. If there is low sunlight and hence output of panel may drop below 12V. For example, panel voltage is $6 \mathrm{~V}$ and we need $12 \mathrm{~V}$ at our vehicle battery, so the charge booster will give the output equals to $18 \mathrm{~V}$. The charge controller connected at the output of charge booster will convert amplified voltage of booster to $12 \mathrm{~V}$ constant. and it is our vehicle battery requirement. The basic function of charge controller is to provide constant voltage as per need. In such a way we can drive our vehicle efficiently in presence of sunlight which not only saves fuel but also helps to keep our environment free from harmful gasses released from vehicle.

As it is a smart vehicle, it also has extra smart parameters like accident detection, monitoring temperature of engine as well as vehicle theft controlling. To imply on such parameters, we need a microcontroller (PIC18F2522) which is programmed in Embedded $\mathrm{C}$ using MPLAB IDE.The microcontroller operates on power supply of $5 \mathrm{~V}$ $\mathrm{DC}$ but the battery voltage is of $12 \mathrm{~V} \mathrm{DC}$, sowe need to regulate this $12 \mathrm{~V}$ DC to $5 \mathrm{~V} \mathrm{DC}$ using voltage regulator. At the input there is a battery voltage block,GPS module (SRIF3),GSMmodule (SIM800L), temperature sensor and vibration sensor. And at the output there is a motor driver IC L293 (operates on 5V DC), LCD $(2 \times 16)$ and a buzzer.

Controller will check that the battery of vehicle is charged or not. If it is mostly discharged, then controller give the command to motor driver that battery has been low and automatically the relay used in motor driver switch over to fuel engine of vehicle and vehicle can be drive continuously without any interruption.

Our project is useful for detecting the accident precisely with the help of sensor and microcontroller. According to our project when a vehicle meets with an accident, a vibration sensor (ADXL335) situated on the vehicle will detect it immediately in response with vehicle tilting and send a message to the microcontroller. The microcontroller then sends the alert message with the help of GSM modem to the relatives, police control room or rescue team (in real time) which will include the location with the help of GPS. The buzzer will also alarm to alert driver about possibility of accident. If there is no causality, then driver can also stop sending messages by a switch provide in the system, which will save the valuable time of rescue team.

The system will also detects overheating of engine which may cause severe accidents or vehicle damage due to burning. The engine may get overheated due to increase in surrounding temperature or due toshortening of engine oil. To minimize or to control this problem a temperature sensor is used. If the temperature of engine sensed by temp. sensor goes to 80 degree or more, then microcontroller displays the alert message on LCD and also buzzer will start beeping which will alert the driver. And if temperature increases up to 90 degreesCelsiusand more then motor or engine will stop automatically as such command already given to microcontroller.

\section{RESULT}

\section{Displayed Output}

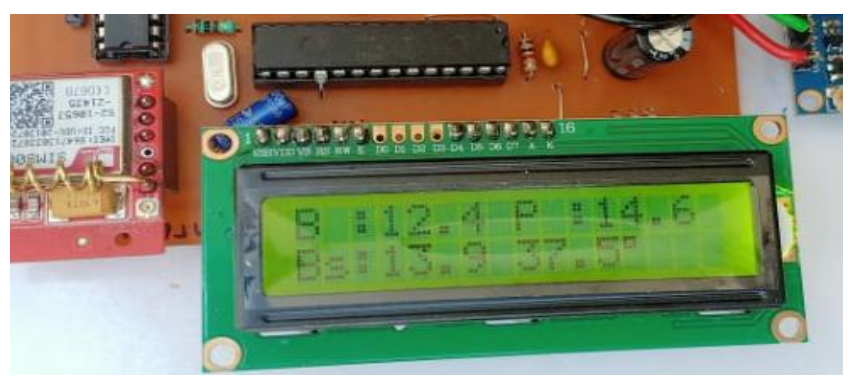

Fig.-5. a) Showing solar panel output with engine temperature

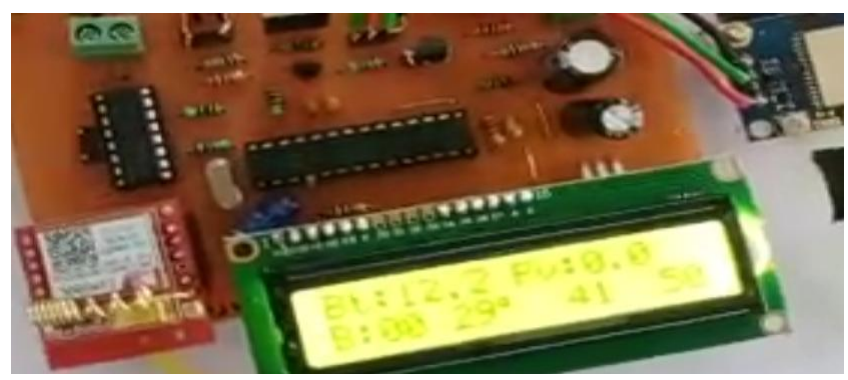

Fig.-5.b)Displays vibration sensor output when vehicle tilted (in case of accident)

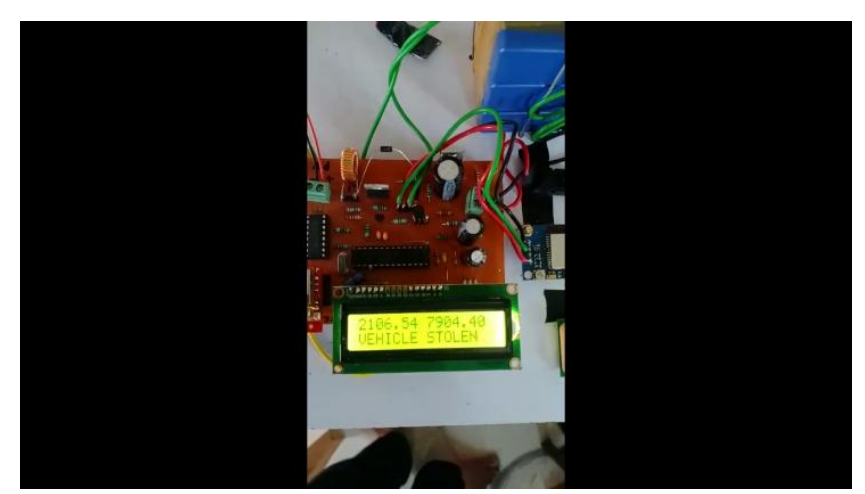




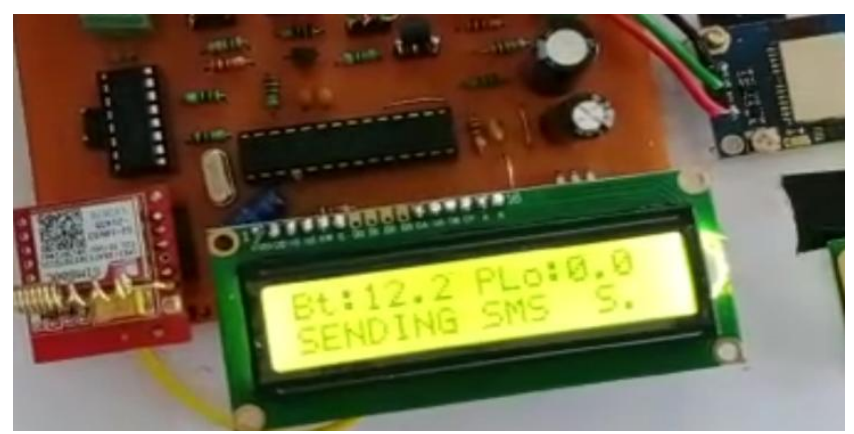

Fig.-5. c)Sending message and location when vehicle stolen

\section{IV- CONCLUSION}

To inbuilt this system in vehicle may be two wheeler or four wheelers will always be affordable because as compared to our vehicle cost this system has low cost.

As the vehicle is running on battery charged by solar voltage, hence the fuel can be saved for future in case when there is very low or no sunlight. The system also very much useful for safety and security point of view. Hence it can be concluded that inbuilt the system in vehicle can be proven very helpful.

\section{V- ADVANTAGES}

- As we are using a non-renewable energy source in the form of sunlight to charge the battery of vehicle which is eco-friendly in nature.

- Using this system in the vehicle we are not only saving thedepleting fuel but can also give our contribution towards nature to be free from air pollution and its causes.

- $\quad$ Provides security against theft.

- Monitors hazards and threats.

- Simple design and can be interfaced with other systems.

- $\quad$ Easy to operate by the user.

- Reliable system.

- Inexpensive to inbuilt the system in the vehicle when compared to the cost of vehicle.

\section{APPLICATIONS}

- This project is applicable in the progress of generating power source through renewal energy.

- Stolen Vehicle Recovery: In case of theft, the vehicle can be tracked by using vehicle positioning system. The GPS system allows the tracking of vehicle from anywhere.

- Fleet Management: When managing a fleet of vehicles, knowing the real-time location of all drivers allows management to meet customer needs more efficiently. Whether it is delivery, service or other multi-vehicle enterprises, drivers now only need a mobile phone with telephony or Internet connection to be inexpensively tracked by and dispatched efficiently.

- Applicable in the crime investigation which involves the vehicle used in criminal activity.

\section{REFERENCES}

[1] N.Uthayabanu, U.Arunkumar, A.Gokulakannan, M.K.Hari Prasad and A.B. Shathish Sharma; "Wireless Power Transfer in Electrical Vehicle by Using Solar Energy", Asian Journal of Electrical Sciences (AJES), Volume: 07, Issue: 1 June-2018. ISSN: 2249-6297, pp. 6-9.

[2] S. J. Gerssen-Gondelach and A. P. C. Faaij; "Performance of batteries for electric vehicles on short and longer term, " $J$. Power Sour., Volume: 212, pp. 111-129, Aug. 2012.

[3] J. N. Rai, Nikhil Gupta, Prashant Bansal; "Design and Analysis of DC-DC Boost Converter”, International Journal of Advance Research and Innovation (IJARI), Volume: 4, Issue: 03 (2016) 499-502, ISSN; 2347-3258.

[4] B. M. Hasaneen and Adel A. Elbaset Mohammed, "Design and Simulation of DC/DC boost converter", Power System Conf. Middle-East, pp. 335-340, 2008.

[5] Sudhakar H S, Indira M S, Gujjala B Balaraju, Siddhartha Bhatt M; "A Study of Boost Converter with Solar Photovoltaic System for Maximum Energy Efficiency", The Journal of CPRI, Volume: 11, No. 1, Issue: March 2015, pp. 133-138.

[6] Nimisha Chaturvedi, Pallika Srivastava; "Automatic Vehicle Accident Detection and Messaging System Using GSM and GPS Modem", International Research Journal of Engineering and Technology (IRJET), Volume: 05, Issue: 03 March-2018 e-ISSN: 23950056, p-ISSN: 2395-0072.

[7] Sri Krishna Chaitanya Varma, Poornesh, Tarun Varma, Harsha "Automatic Vehicle Accident Detection and Messaging System Using GPS and GSM Modems", International Journal of Scientific \& Engineering Research (IJSER), Volume 4, Issue: 8 August-2013 ISSN 2229-5518.

[8] Miss. S.S. Kanase, Miss. S.A. Yadav, Mr. S.B. Jadhav, Prof. M.M. Kadam;" GSM \& GPS Based Vehicle Theft Control System” International Research Journal of Engineering and Technology (IRJET), Volume: 05,Issue: 03 March-2018 e-ISSN: 2395-0056, p-ISSN: 2395-0072

[9] Pankaj Verma, J. S. Bhatia; "Design and development of GPS-GSM based tracking system with google map based monitoring”, International Journal of computer Science, Engineering and Application (IJCSEA) Volume: 03, Issue: 3 June- 2013. 